\title{
FÍSICA E SURDEZ: ESTRATÉGIAS E RECURSOS DIDÁTICOS PARA O ENSINO DA PRIMEIRA LEI DE NEWTON
}

\section{PHYSICS AND DEAFNESS: STRATEGIES AND DIDACTIC RESOURCES FOR TEACHING NEWTON'S FIRST LAW}

\author{
Lucia da Cruz de Almeida ${ }^{1}$, Viviane Medeiros Tavares Mota ${ }^{2}$, Jonathas de Albuquerque \\ Abreu $^{3}$, Ruth Mariani ${ }^{4}$ \\ ${ }^{1}$ UFF/Departamento de Física/PPG em Ensino de Ciências da Natureza, lucia@if.uff.br \\ ${ }^{2}$ UFF/Curso de Licenciatura em Física, viiivianee@ fisica.if.uff.br \\ ${ }^{3}$ UFF/Curso de Licenciatura em Física, jaaslp@ fisica.if.uff.br \\ ${ }^{4} \mathrm{SEE} /$ Instituto de Educação Professor Ismael Coutinho, ruthmariani@yahoo.com.br
}

\begin{abstract}
RESUMO
Apresentamos o relato de uma experiência sobre o ensino da $1^{\mathrm{a}}$ Lei de Newton para 12 alunos surdos de uma escola pública. Tomando por base as especificidades da comunicação com alunos surdos, licenciandos em Física foram desafiados a refletir sobre a prática docente, propor e implementar atividade de ensino adequada aos pressupostos da educação inclusiva. Além do enriquecimento da formação docente, objetivávamos produzir material didático alternativo ao ensino expositivo e que permitisse ao aluno surdo plena participação na construção do conhecimento. Os resultados se mostraram satisfatórios, tanto em relação à formação dos licenciandos quanto à adequação dos recursos e estratégias didáticas propostas para os processos de ensino e de aprendizagem. A atividade de ensino está sendo consolidada na forma de vídeo bilíngue, de modo a permitir seu acesso a outros professores e, consequentemente, contribuir para a ampliação de recursos alternativos ao ensino expositivo.
\end{abstract}

Palavras-chave: Educação inclusiva; surdez; ensino de Física; material didático; prática docente.

\begin{abstract}
We report an experiment on the teaching of Newton's 1st Law for 12 deaf students from a public school. Based on the specifics of communication with deaf students, undergraduates in Physics were challenged to reflect on teaching practices, propose and implement appropriate educational activity to the assumptions of inclusive education. In addition to the enrichment of teacher education, we aim to produce alternative courseware expository teaching and enabling the deaf student full participation in the construction of knowledge. The results were satisfactory, both in relation to the training of undergraduates as to the adequacy of resources and teaching strategies proposed for the processes of teaching and learning. Teaching activities are being consolidated in the form of bilingual video, to allow access to other teachers and, consequently, contribute to the expansion of alternatives to expository teaching resources.
\end{abstract}

Key words: Inclusive education; deafness; Physics teaching; didactic material; teaching practice

\section{INTRODUÇÃOO}

A política educacional brasileira representa um avanço no processo de inclusão de deficientes, já que o acesso à escola regular está garantido (CNE/CEB, 2001; 


\title{
Ensino, Saúde e Ambiente - V 7 (1), Edição Especial, maio de 2014
}

MEC/SEESP, 2007; BRASIL, 2013). Teoricamente, não cabe mais ao deficiente se adaptar à escola, tendo em vista que:

\begin{abstract}
A educação inclusiva pressupõe novas relações pedagógicas centradas nos modos de aprender das diferentes crianças e jovens e de relações sociais que valorizam a diversidade em todas as atividades, espaços e formas de convivência e trabalho. Dessa forma, na efetivação do direito de todos à educação, o direito à igualdade e o direito à diferença são indissociáveis e os direitos específicos servem para eliminar as discriminações e garantir a plena inclusão social (MEC, 2006, p.5).
\end{abstract}

Na prática, porém, a inclusão está condicionada à reestruturação/adaptação da escola aos deficientes, no sentido de garantir-lhes não apenas a presença, mas, principalmente, a participação e a aquisição de conhecimentos (AINSCOW, s/d).

Apesar do Decreto No 5.626 de 22 de dezembro de 2005 (BRASIL, 2005), que visa garantir ao deficiente auditivo o acesso à comunicação, à informação e à educação nos processos seletivos, nas atividades e nos conteúdos curriculares desenvolvidos em todos os níveis, etapas e modalidades de educação, a comunicação ainda se apresenta como o principal obstáculo à educação do aluno surdo na perspectiva da inclusão.

Em relação ao ensino de Ciências, a questão da comunicação como obstáculo ao processo de aprendizagem se agrava. Barral, Pinto-Silva e Rumjanek (2012, p.30) ressaltam que no ensino de ciências são enfocados conceitos abstratos, contudo, a cultura dos surdos baseia-se na realidade. Além disso, esses autores, tal como Ramos (2013, p. 3), constataram que na Língua Brasileira de Sinais (Libras) são pouquíssimos os sinais que correspondem às palavras que sintetizam os conceitos científicos de Ciências. Em outras palavras, a Libras é pobre na terminologia científica, dificultando o acesso do aluno surdo ao conhecimento científico.

Em relação ao ensino de Física, nas últimas décadas, as pesquisas geraram recomendações para a melhoria dos processos de ensino de aprendizagem, porém, em relação à inclusão de alunos surdos, as sugestões de recursos e estratégias didáticas ainda são escassas (COZENDEY; COSTA; PESSANHA, 2011, p. 628; MEDEIROS; MUSSI; LEVADA, 2012).

De uma maneira geral, o ensino de Física que privilegia a oralidade e a escrita do professor não tem se mostrado adequado à aquisição do conhecimento por parte dos alunos da Educação Básica. No que se refere ao aluno surdo, pelas questões apresentadas sobre a Libras e a linguagem científica, essa forma de abordagem dos conteúdos dificulta ainda mais a sua participação e, consequentemente, a sua aprendizagem. Dessa forma, um ensino de Física na perspectiva da inclusão do surdo 


\title{
Ensino, Saúde e Ambiente - V 7 (1), Edição Especial, maio de 2014
}

em classes comuns do ensino regular deve recorrer a recursos e estratégias de ensino que, por um lado, não se reduzam a exploração da audição e, por outro, favoreçam a ampliação de sinais que expressem grandezas e conceitos físicos.

Ressaltamos que no processo de criação de sinais é fortemente recomendada a participação do surdo, do especialista na área de conhecimento e do especialista em educação de surdos ${ }^{1}$.

Sobre os recursos e estratégias de ensino, geralmente, os professores têm demonstrado dificuldades na proposição e realização de atividades didáticas eficazes na consolidação da inclusão dos alunos surdos. Nesse sentido, a familiarização de professores e futuros professores com o ensino de Física para surdos, de modo a oportunizá-los a vivenciar uma prática docente reflexiva, tem sido apontada como um processo relevante na consolidação da inclusão no contexto escolar. Siems (2010) defende a construção de outra profissionalidade para os docentes:

\begin{abstract}
uma formação que tenha como foco uma atuação docente que considere a diversidade, o Múltiplo, como fator de enriquecimento das relações humanas, em que o trabalho educacional atinja a todos que dele necessitam, sem o deslocar dessa responsabilidade para especialistas, que têm também um importante papel, mas cuja atuação não pode ser confundida com a função educativa e nem substituí-la (p. 37).
\end{abstract}

Neste trabalho apresentaremos o relato de uma experiência que, por meio de vivências com o ensino de Física para surdos, teve como principais objetivos: oportunizar a professores em formação inicial o processo de construção de uma prática docente coerente com os pressupostos da educação inclusiva; produzir material didático alternativo ao ensino expositivo e que permitisse ao aluno surdo plena participação na construção do conhecimento; contribuir para a ampliação de sinais, mesmo que provisórios, relativos a grandezas e conceitos físicos; produzir e divulgar na Internet vídeo didático bilíngue (áudio e texto na Língua Portuguesa e legendas em LIBRAS).

\section{MATERIAL E ESTRATÉGIA DIDÁTICA}

O tema selecionado para a elaboração da atividade de ensino foi Primeira Lei de Newton. Como os dois licenciandos envolvidos não tinham conhecimento prévio dos marcos e pressupostos balizadores da educação inclusiva, incluindo aqueles relativos à educação de surdos, houve a necessidade de um aprofundamento teórico do assunto.

Assim, na elaboração da proposta de atividade de ensino procuramos contemplar os aspectos inerentes à abordagem construtivista dos conteúdos e a

\footnotetext{
${ }^{1}$ I Simpósio Nacional sobre Desenvolvimento de Produtos e Processos na Perspectiva da Surdez: Sinais em Foco, 2013.

Edição Especial com os melhores trabalhos apresentados no IV ENECiências: UFF - 13 a 16 de maio de 2014. 
percepção do conhecimento por alunos ouvintes e surdos, de modo que a sua implementação pudesse favorecer: a explicitação de concepções prévias; a elaboração hipóteses, a manipulação de material concreto; a visualização do fenômeno; a evolução conceitual; o reconhecimento do conteúdo em situações cotidianas. Sequencialmente, a atividade de ensino pode ser descrita por três etapas: problematização do conteúdo, sistematização ou modelização e contextualização.

Para a problematização do conteúdo foram formuladas perguntas-chave associadas a imagens ilustrativas, como as exemplificadas nas Figuras 1 e 2.

Figura 1: Exemplo de pergunta-chave
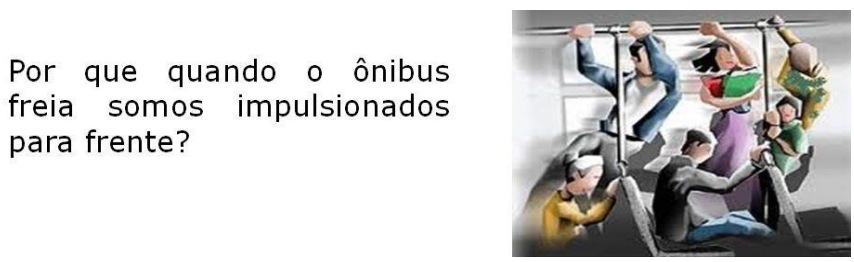

Fonte: imagem disponível em http://www.alunosonline.com.br/fisica/primeira-lei-newton.html

Figura 2: Exemplo de pergunta-chave

$$
\begin{aligned}
& \text { Vocês acham que a Ciência } \\
& \text { pode explicar obrigatoriedade } \\
& \text { do uso do cinto de segurança? }
\end{aligned}
$$

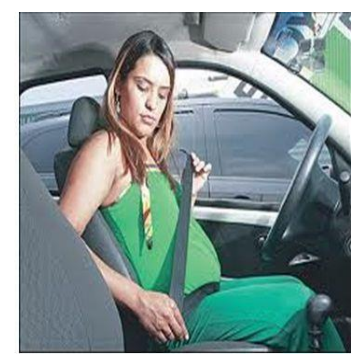

Fonte: imagem disponível em http://autochecksaude.com.br/wp_acs/?p=678

Para a construção do conhecimento científico pelos alunos, mediada pela ação do professor (sistematização/modelização do conteúdo) foi selecionado e construído um experimento simples que, além de favorecer a explicitação de concepções, não oferecia riscos aos alunos durante sua manipulação. A Figura 3 ilustra essa etapa da atividade.

Figura 3: Ilustração do experimento

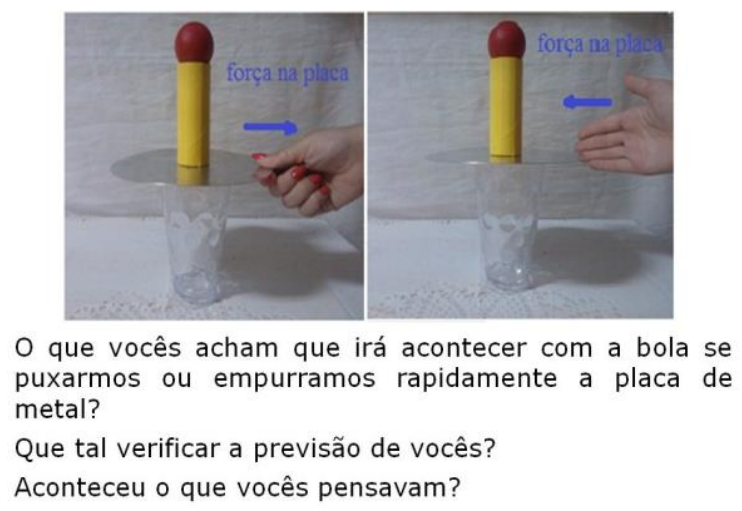

Fonte: autores

Edição Especial com os melhores trabalhos apresentados no IV ENECiências: UFF - 13 a 16 de maio de 2014. 


\section{Ensino, Saúde e Ambiente - V 7 (1), Edição Especial, maio de 2014}

Na contextualização do conhecimento, além do retorno às perguntas-chave reelaboração das respostas com base no modelo científico, foi proposto o uso do vídeo Campanha Motociclista 2013 - Parada pela vida ${ }^{2}$.

A fim de proporcionar uma melhor percepção do conteúdo da atividade de ensino em suas diferentes etapas, a mesma foi organizada em slides para a apresentação aos alunos com o uso de recursos multimídia.

A atividade de ensino, a partir de algumas adequações, foi consolidada na forma de um vídeo monoconceitual, de curta duração, com imagens e textos em português, de modo a vir servir de matéria-prima na produção do vídeo bilíngue (texto e áudio em português com legendas em Libras).

\section{REALIZAÇÃO DA ATIVIDADE DE ENSINO}

A atividade de ensino foi realizada na Sala de Recursos Multifuncionais de uma escola pública da rede estadual do Rio de Janeiro e contou com a participação de 12 alunos surdos que se encontravam em diferentes níveis/anos de escolarização, conforme descrição na Tabela 1.

Tabela 1: Ano/ Nível escolar dos alunos que constituíram a amostra

\begin{tabular}{|l|l|l|}
\hline \multirow{3}{*}{ Nível de Ensino } & Ano & $\mathbf{N}^{\mathbf{o}}$ de Alunos \\
\hline \multirow{3}{*}{ Médio } & $1^{\circ}$ & 1 \\
\cline { 2 - 3 } & $2^{\circ}$ & 1 \\
\hline \multirow{4}{*}{$2^{\circ}$ Segmento do Ensino Fundamental } & $7^{\circ}$ & 3 \\
\cline { 2 - 3 } & $8^{\circ}$ & 2 \\
\cline { 2 - 3 } & $9^{\circ}$ & 5 \\
\hline
\end{tabular}

A atividade ocorreu no último bimestre do ano letivo de 2013 e nenhum aluno tinha estudado formalmente a Lei da Inércia e sequer vislumbravam quem foi Isaac Newton.

Coube aos licenciandos em Física a aplicação da proposta de ensino. Para tanto, contaram com a colaboração de uma intérprete/tradutora em LIBRAS e a supervisão de duas docentes especialistas, respectivamente, em Física e em Educação Especial.

A atividade transcorreu no contra turno de matrícula dos alunos, com a duração de aproximadamente dois tempos de aula de $50 \mathrm{~min}$.

\section{RESULTADOS}

\footnotetext{
${ }^{2}$ http://www.paradapelavida.com.br/campanhas/campanha-motociclista-2013/

Edição Especial com os melhores trabalhos apresentados no IV ENECiências: UFF - 13 a 16 de maio de 2014. 


\section{Ensino, Saúde e Ambiente - V 7 (1), Edição Especial, maio de 2014}

Em relação aos alunos surdos, os resultados decorrem de observações livres das docentes, licenciandos e intérprete/tradutora.

O uso de projeção de imagens e textos, bem como o experimento, foram fatores preponderantes no envolvimento e motivação dos alunos durante atividade.

Tal como supúnhamos, a apresentação de situações próximas às vivências dos alunos (perguntas-chave) despertou o interesse pela a busca de respostas aceitas pela Ciência.

O experimento foi fundamental na elaboração de hipóteses e na modelização do conteúdo. Inicialmente, os alunos supunham que ao puxar ou empurrar a placa, a bola cairia antes ou depois, mas nunca dentro do copo. No confronto de suas previsões com a realização do experimento, os alunos se mostraram sensíveis à reformulação de suas ideias, o que facilitou a modelização do conteúdo.

Após o processo de ensino, os alunos conseguiram correlacionar razoavelmente as situações apresentadas nas perguntas-chave e no vídeo Campanha Motociclista 2013 - Parada pela vida com o enunciado da $1^{\mathrm{a}}$ Lei de Newton.

Cabe ressaltar que o conhecimento prévio da atividade de ensino por parte da intérprete/tradutora, devido à escassez de sinais relativos à Física, se mostrou essencial na veiculação e compreensão do conteúdo da atividade.

No que tange aos licenciandos, houve um enriquecimento da prática docente. A apreensão presente na elaboração da atividade de ensino foi se diluindo no decorrer da atuação junto aos alunos. Houve surpresa e mudança de concepção com relação à prática docente e à participação dos alunos. Inicialmente, não se sentiam seguros na realização da atividade como professores e esperavam encontrar alunos apáticos e com aversão à Física. Puderam perceber, dentre outros aspectos, que: os alunos surdos têm interesse e podem aprender Física; há necessidade de ações que favoreçam ao deficiente auditivo o acesso ao conhecimento científico, incluindo aquelas oportunizem a criação de sinais associados à terminologia usada nas Ciências Naturais; as estratégias, recursos didáticos e ação docente são fatores preponderantes no envolvimento de qualquer aluno no processo de ensino e, consequentemente, na aprendizagem do conteúdo proposto; a reflexão e proposição de situações de aprendizagem que atendam aos alunos surdos podem resultar na melhoria da qualidade de ensino de todos os alunos; o domínio da Libras por parte do professor é fundamental na implementação de práticas dialógicas em sala de aula; sem mudança na prática docente não haverá consolidação da educação inclusiva no contexto escolar.

Edição Especial com os melhores trabalhos apresentados no IV ENECiências: UFF - 13 a 16 de maio de 2014. 


\section{Ensino, Saúde e Ambiente - V 7 (1), Edição Especial, maio de 2014}

A realização da atividade confirmou a importância do diálogo entre professores generalistas, no caso deste trabalho docente e licenciandos da área de Física, professor especialista em educação especial e intérprete/tradutor.

Em relação ao vídeo bilíngue, após a realização da atividade de ensino e da apresentação do vídeo (matéria prima) descrito anteriormente, uma aluna surda aceitou nosso convite para ser intérprete das legendas em Libras.

Esse processo demandou mais tempo, já que houve a necessidade de: uma análise mais detalhada dos textos constantes do vídeo por parte da intérprete/tradutora; consulta a dicionários da Língua de Sinais para a verificação da existência de sinais para palavras e termos com conotação científica presentes no vídeo; criação de sinais provisórios para a compreensão do conteúdo do vídeo.

Ressaltamos que na criação de sinais houve a participação da aluna surda, da intérprete/tradutora, dos licenciandos e dos professores especialistas em Física e em Educação Especial.

Vários sinais foram criados, permitindo a produção e filmagem das legendas em Libras e a reedição do vídeo (matéria prima) com a inserção do áudio e das legendas em Libras. As Fotos 1 e 2 ilustram, respectivamente, momentos de criação de sinais e filmagem de legendas.

Foto 1: Criação de sinais ${ }^{3}$

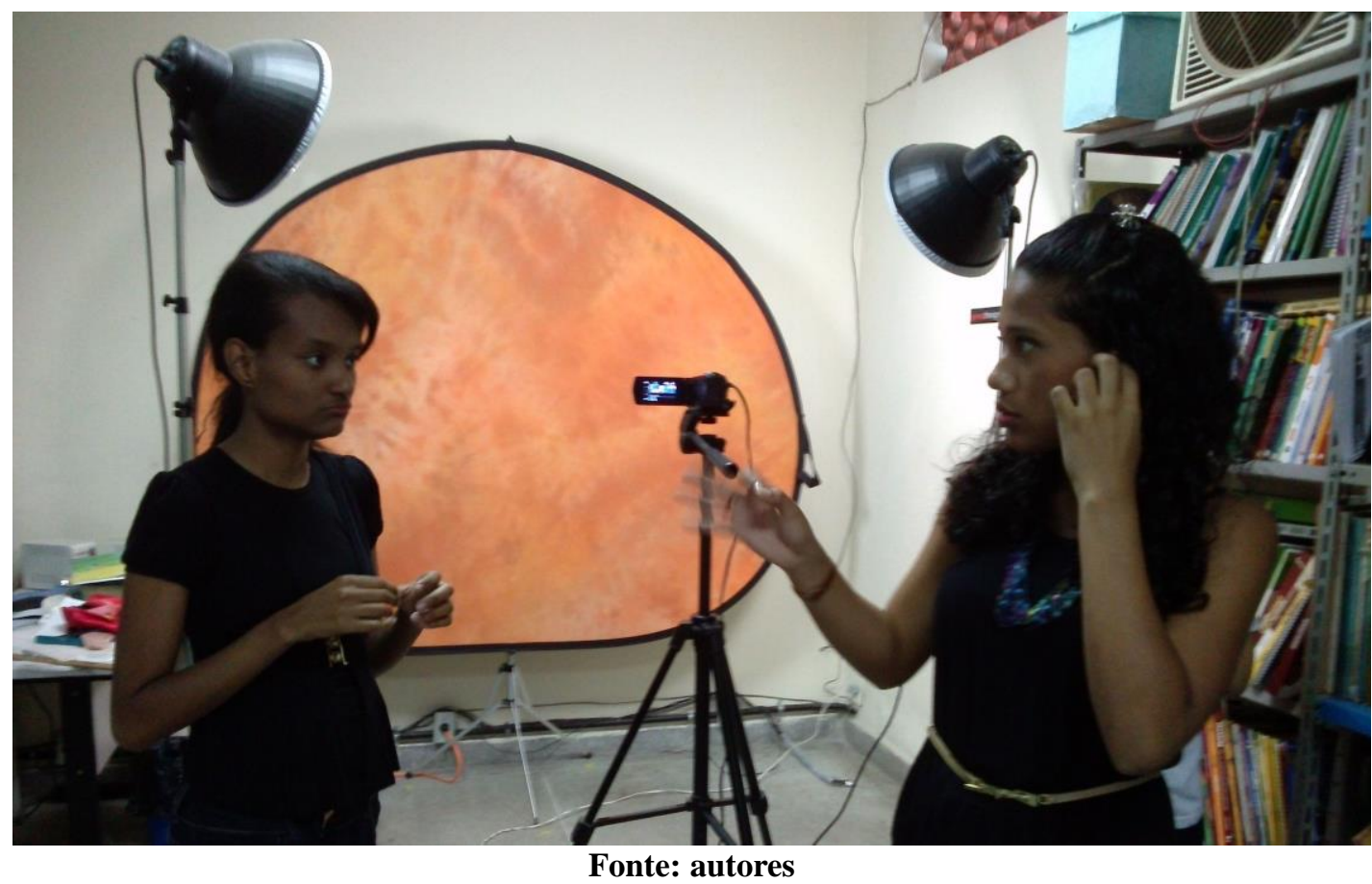

\footnotetext{
3 A Sala de Recursos Multifuncionais da escola possui autorização formal para o uso de imagens dos envolvidos.

Edição Especial com os melhores trabalhos apresentados no IV ENECiências: UFF - 13 a 16 de maio de 2014. 
Foto 2: Filmagem de legendas para o vídeo bilíngue.

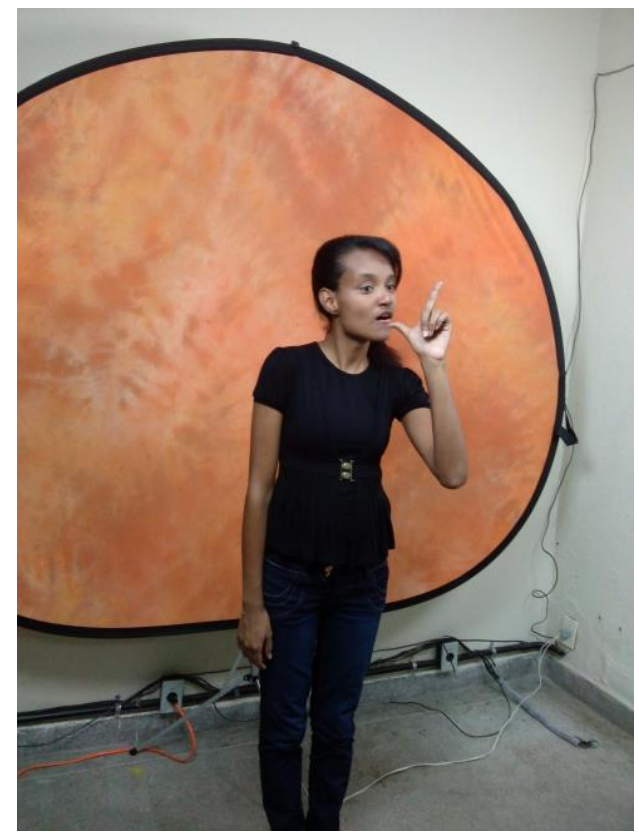

Fonte: autores

\section{CONSIDERAÇÕES FINAIS}

As interações entre professor-alunos, aluno-aluno e aluno-material didático têm sido colocadas como de fundamental importância no processo de aquisição de novos conhecimentos. Nesse sentido, a comunicação com alunos surdos em aulas de Física do Ensino Médio tem ficado prejudicada em decorrência da falta de domínio da Língua Brasileira de Sinais (LIBRAS) por todos os envolvidos no processo de ensino e, também, pela escassez de sinais que expressem a linguagem científica.

A partir de vivências com o ensino de Física para surdos, confirmamos que o fazer docente e o uso de recursos e estratégias didáticas que torne o conteúdo escolar mais próximo e perceptível ao aluno são fundamentais no processo de aprendizagem. Nesse sentido, sem descartar a necessidade de mudanças estruturais e organizacionais da escola, é possível afirmar que a consolidação da educação inclusiva está condicionada a mudanças efetivas nos cursos de formação de professores. Os Cursos de Licenciatura devem criar mecanismos que favoreçam aos futuros professores a construção de uma prática docente coerente com os pressupostos da educação inclusiva.

A implementação de atividades didático-metodológicas facilitadoras no acesso ao conhecimento científico pelos surdos fazem aflorar a carência de sinais relativos aos conteúdos de Física. Entretanto, será por meio da compreensão desses conteúdos pelos surdos que esse déficit poderá ser suprido. O processo de criação de novos sinais está 
condicionado à participação do surdo e, sendo assim, a compreensão daquilo que pretende expressar pela linguagem gestual é essencial.

A nosso ver, a veiculação do vídeo didático bilíngue na Internet ${ }^{4}$, bem como seu uso por outros professores de Física, apesar de ser restrito a um conteúdo - $1^{\mathrm{a}}$ Lei de Newton - se configura como um resultado significativo no processo de inclusão de alunos surdos em aulas de Física.

Por fim, ressaltamos que a reflexão-ação docente em prol da inclusão dos deficientes auditivos resultará em melhoria na qualidade de ensino de todos os alunos.

\section{REFERÊNCIAS}

AINSCOW, M.. Processo de Inclusão é um processo de aprendizado (entrevista).

Disponível em http://www.crmariocovas.sp.gov.br/ees_a.php?t=002. Acessado em 28 de março de 2012.

BARRAL, J.; PINTO-SILVA, F. E.; RUMJANEK, V. M. Comunicando ciência com as mãos: o acesso difícil dos surdos ao saber científico. Ciência Hoje, v. 50, setembro, p. 26-31, 2012.

BRASIL. Lei No 12.796, de 4 de abril de 2013. 2013. Disponível em http://www.planalto.gov.br/ccivil_03/_Ato2011-2014/2013/Lei/L12796.htm\#art1. Acessado em 20 de maio de 2013. . Decreto $\mathrm{N}^{\circ} 5.626$ de 22 de dezembro de 2005. Disponível em http://www.planalto.gov.br/ccivil_03/_ato2004-2006/2005/decreto/d5626.htm. Acessado em 11 de novembro de 2013.

CNE/CNB. Diretrizes Nacionais para a Educação Especial na Educação Básica. Brasília, DF, 2001. Disponível em http://portal.mec.gov.br/seesp/arquivos/pdf/diretrizes.pdf. Acessado em 28 de fevereiro d 2013.

COZENDEY, S. G.; COSTA, M. P. R.; PESSANHA, M. C. R.. Uma proposta diferenciada para ensinar leis de Newton em turmas inclusivas. In: VII Encontro da

Associação Brasileira de Pesquisadores em Educação Especial, Londrina, 2011.

Disponível em:

http://www.uel.br/eventos/congressomultidisciplinar/pages/anais/2011/processo_inclusi vo/058-2011.pdf. Acessado em 10 de dezembro de 2012.

MEC/SEESP. Política Nacional de Educação Especial na Perspectiva da Educação Inclusiva. MEC/SEESP, 2007. Disponível em:

http://portal.mec.gov.br/seesp/arquivos/pdf/politica.pdf. Acessado em 26 de janeiro de 2013.

Direito à educação: subsídios para a gestão dos sistemas educacionais orientações gerais e marcos legais. BLATTES, R. L. (Org). 2 ed, Brasília: MEC, SEESP, 2006. Disponível em:

http://portal.mec.gov.br/seesp/arquivos/pdf/direitoaeducacao.pdf. Acessado em 12 de dezembro de 2013.

MEDEIROS, R.; MUSSI, A. A.; LEVADA, C. L. Ensino de Física para alunos surdos: desafios e possibilidades. Revista Virtual Partes, 2009. Disponível em:

\footnotetext{
${ }^{4}$ Disponível em: http://www.youtube.com/watch?v=vZWvF80LVKI\&list=UU17kwRiIfCK1 mI69X9QT7Q

Edição Especial com os melhores trabalhos apresentados no IV ENECiências: UFF - 13 a 16 de maio de 2014. 
http://www.partes.com.br/educacao/fisicaparasurdos.asp. Acessado em 03 de fevereiro de 2014.

RAMOS, D. P. O ensino de Ciências em Libras para surdos: Energia Potencial e Cinética em vídeos on-line. In: Anais do I Simpósio Internacional de Estudos sobre a Deficiência - SEDPcD/Diversitas/USP Legal, São Paulo, 2013. Disponível em:

http://www.memorialdainclusao.sp.gov.br/br/ebook/Textos/Danilo_Prado_Ramos.pdf. Acessado em 04 de janeiro de 2014.

SIEMS, Maria Edith Romano. Educação especial em tempos de educação inclusiva: identidade docente em questão. São Carlos: Pedro \& João Editores, 2010. 